\title{
Are Volatile Organic Compounds Able to Identify Airflow Decline in Asthma?
}

This article was published in the following Dove Press journal:

Journal of Asthma and Allergy

\author{
Sophie Graff $\left.{ }^{\prime}\right)^{\prime}$ \\ Delphine Zanella ${ }^{2}$ \\ Pierre-Hugues Stefanuto ${ }^{2}$ \\ Monique Henket' \\ Virginie Paulus' \\ Francoise Guissard' \\ Catherine Moermans (iD ${ }^{\prime}$ \\ Kristel Van Steen ${ }^{3}$ \\ Renaud Louis' \\ Florence Schleich' \\ 'Department of Respiratory Medicine, \\ GIGA I ${ }^{3}$, CHU Sart-Tilman, Liege, \\ Belgium; ${ }^{2}$ Organic and Biological \\ Analytical Chemistry Group, University \\ of Liege, Liege, Belgium; ${ }^{3} \mathrm{BIO} 3-$ Systems \\ Genetics, GIGA-R, University of Liege, \\ Liege, Belgium
}

Asthma is a chronic inflammatory disease of the airways. Asthmatics are at risk of developing structural changes resulting in persistent airflow limitations and remodeling. ${ }^{1}$ On average, asthma patients have lower lung function than healthy individuals and their lung function $\left(\mathrm{FEV}_{1}\right)$ decline can be greater over time. ${ }^{1}$ Nevertheless, not all asthma patients decline over time; some show stable lung function while others can outgrow their asthma disease. ${ }^{2}$ Previous studies have revealed risk factors for accelerated $\mathrm{FEV}_{1}$ decline in asthma including airway inflammation. Indeed, high eosinophil sputum numbers, ${ }^{2}$ as well as higher blood eosinophil numbers ${ }^{3}$ have been linked to the accelerated rate of lung function decline in asthma. Analysis of exhaled breath for endogenously generated volatile organic compounds (VOCs) has previously been found to be able to noninvasively differentiate eosinophilic from neutrophilic asthma. ${ }^{4}$ In a previous study, we were also able to identify in vitro VOCs discriminating between eosinophil and neutrophil cultures, regardless the activation status. ${ }^{5}$ As VOCs are able to reflect inflammation, ${ }^{4}$ we were interested to evaluate if VOCs are able to quantify airflow decline in asthma. VOC measurements could be an easy and non-invasive way to identify ongoing airflow decline in asthmatic for whom no prior measurement of lung function was available. This could have an impact on the follow-up visit schedule and treatment regimen.

We conducted a prospective study on a population of unselected asthmatics recruited from the University Asthma Clinic of Liege after gaining fully informed written consent and with approval from the ethics committee of CHU Liège (2005/ 181) in accordance with the Helsinki Declaration. Patients underwent measurements of fraction of exhaled nitric oxide (FeNO), spirometry, sputum induction, and gave a blood sample at two time points (baseline and 5 years later). VOC measurements were collected once at the 5-year-follow-up visit. Subjects with asthma were allocated in two groups (airflow decliners and non-decliners) retrospectively according to their lung function (post-BD FEV ${ }_{1}$ ) decline per year calculated as by subtracting the follow-up measured value from the baseline post-BD $\mathrm{FEV}_{1}$, subdivided by the number of months separating the two measurements, and multiplied by 12 . Decline was defined as a loss of $\mathrm{FEV}_{1}$ (\% predicted)/year greater than zero. The thermal desorption tubes, containing the exhaled breath of the patients were desorbed onto a Pegasus 4D HRT (LECO Corporation, St. Joseph, MI, USA) GC $\times$ GC-HR ToF MS instrument with an Agilent 7890 GC equipped with a TD100-xr thermal desorber (Markes International Ltd.). The data were acquired and analyzed using ChromaTOF HRT software, version 5.20 (LECO Corporation) and GC Image software version
Correspondence: Sophie Graff

Department of Respiratory Medicine,

CHU Sart-Tilman, GIGA +4, CHU - B34,

Avenue de l'Hôpital, II, Liège 4000,

Belgium

Tel +3243664592

Email sgraff@uliege.be
Journal of Asthma and Allergy 2021:14 67-70

67

DovePress if in $>$

http://doi.org// 0.21 477/JAA.S289278 
Table I Demographic, Clinical and Inflammatory Characteristics at Baseline of Asthmatics with VOC Measurements $(n=45)$

\begin{tabular}{|c|c|c|c|}
\hline Characteristics & No Decline & $\begin{array}{l}\text { Airflow } \\
\text { Decline }\end{array}$ & p-value \\
\hline$N(\%)$ & $25(56)$ & $20(44)$ & \\
\hline Women (\%) & $13(65)$ & $15(60)$ & 0.767 \\
\hline Age (years) & $48 \pm 13$ & $53 \pm 14$ & 0.2380 \\
\hline BMI $\left(\mathrm{kg} / \mathrm{m}^{2}\right)$ & $25 \pm 3$ & $26 \pm 4$ & 0.6842 \\
\hline Atopy (Y) (\%) & $10(53)$ & $12(50)$ & 0.999 \\
\hline \multicolumn{4}{|l|}{ Smoking status (\%) } \\
\hline - Never smokers & $9(45)$ & $12(52)$ & \multirow[t]{3}{*}{0.483} \\
\hline - Current smokers & $6(30)$ & $3(13)$ & \\
\hline - Ex-smokers & $5(25)$ & $8(35)$ & \\
\hline Age of onset (years) & $37 \pm 15$ & $38 \pm 22$ & 0.9296 \\
\hline Disease duration (years) & $11 \pm 16$ & $17 \pm 14$ & 0.2150 \\
\hline Post-BD FEV I (L) & $2.65 \pm 0.98$ & $2.38 \pm 0.72$ & 0.2830 \\
\hline $\begin{array}{l}\text { Post-BD FEV } / \text { FVC (\% } \\
\text { pred) }\end{array}$ & $74 \pm 11$ & $67 \pm 12$ & 0.0494 \\
\hline Reversibility (\%) & $4.32 \pm 6.29$ & $7.48 \pm 7.93$ & 0.1601 \\
\hline ACT score & $13 \pm 5.5$ & $16.7 \pm 5.2$ & 0.0455 \\
\hline ACQ score & $2.5 \pm 1.4$ & $2.0 \pm 1.1$ & 0.2343 \\
\hline AQLQ score & $4.1 \pm 1.5$ & $4.4 \pm 1.4$ & 0.3979 \\
\hline $\mathrm{FeNO}(\mathrm{ppb})$ & 39 (I6-7I) & $29(19-45)$ & 0.6473 \\
\hline $\begin{array}{l}\text { Sputum eosinophil count } \\
\text { (\% of non-squamous } \\
\text { cells) }\end{array}$ & $4.3(0.1-50.7)$ & $3.4(0.8-5.4)$ & 0.4155 \\
\hline $\begin{array}{l}\text { Sputum neutrophils } \\
\text { count (\% of non- } \\
\text { squamous cells) }\end{array}$ & $\begin{array}{l}36.7 \\
(17.6-60.6)\end{array}$ & $\begin{array}{l}54.3(25.8 \\
-66.2)\end{array}$ & 0.4044 \\
\hline Blood eosinophils $(/ \mu \mathrm{L})$ & $\begin{array}{l}223 \\
(116-594)\end{array}$ & $162(92-228)$ & 0.1534 \\
\hline Blood neutrophils $(/ \mu \mathrm{L})$ & $\begin{array}{l}4701 \\
(3898-5796)\end{array}$ & $\begin{array}{l}3988 \\
(3162-4366)\end{array}$ & 0.1150 \\
\hline Total serum IgE (kU/L) & $126(66-280)$ & 191 (49-489) & 0.4587 \\
\hline CRP (mg/L) & $2(I-6)$ & $2(0.5-5)$ & 0.6289 \\
\hline Fibrinogen (g/L) & $4(3-4)$ & $4(3-4)$ & 0.8299 \\
\hline ICS daily dose ( $\mu \mathrm{g} /$ day) & $\begin{array}{l}1000 \\
(200-1700)\end{array}$ & $\begin{array}{l}1225 \\
(250-2000)\end{array}$ & 0.4299 \\
\hline ICS category (\%) & & & \\
\hline
\end{tabular}

(Continued)
Table I (Continued)

\begin{tabular}{|c|c|c|c|}
\hline Characteristics & No Decline & $\begin{array}{l}\text { Airflow } \\
\text { Decline }\end{array}$ & p-value \\
\hline - Steroid naïve & $5(25 \%)$ & $6(25 \%)$ & \multirow[t]{4}{*}{0.349} \\
\hline - Low dose & I (5\%) & $2(8 \%)$ & \\
\hline - Medium dose & 7 (35\%) & $3(12 \%)$ & \\
\hline - High dose & $5(25 \%)$ & $13(54 \%)$ & \\
\hline LABA, N (\%) & $15(75)$ & $15(60)$ & 0.352 \\
\hline LAMA, N (\%) & I (5) & $5(20)$ & 0.205 \\
\hline OCS therapy, $\mathrm{N}(\%)$ & $2(10)$ & $4(16)$ & 0.678 \\
\hline $\begin{array}{l}\text { Biologic therapy (anti- } \\
\text { lgE) }\end{array}$ & $0(0)$ & I (4) & 1.000 \\
\hline $\begin{array}{l}\text { Exacerbations in } \\
\text { previous year }\end{array}$ & $I(0-1)$ & $I(0-I)$ & 0.5916 \\
\hline $\begin{array}{l}\text { Hospitalizations in } \\
\text { previous year }\end{array}$ & $0(0-1)$ & $0(0-1)$ & 0.9371 \\
\hline
\end{tabular}

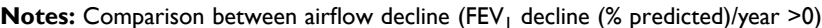
and no decline groups in asthma. Data are presented as mean \pm SD or median and

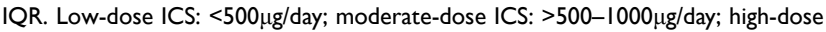
ICS: > $1000 \mu \mathrm{g} /$ day beclomethasone dipropionate - chlorofluorocarbon.

Abbreviations: BMI, body mass index; BD, bronchodilation; $F E V_{1}$, forced expiratory volume in Is; FVC, forced vital capacity; ACT, Asthma Control Test; ACQ, Asthma Control Questionnaire; AQLQ, Asthma Quality of Life Questionnaire; FeNO, fractional exhaled nitric oxide; ppb, parts per billion; ICS, inhaled corticosteroid; LABA, long-acting B2-agonist; LAMA, long-acting muscarinic antagonist; OCS, oral corticosteroid.

2.5HRMS ${ }^{\circledR}$. Analysis of the data output files was performed in successive steps as previously described. ${ }^{6}$ The identification of the VOCs was performed following high analytical standards (bi-dimensional chromatographic retention times and mass spectral matching factors). To estimate the discrimination importance of each VOC, conditional inference forest algorithm ${ }^{7}$ along with variable importance measure were used to assess the discriminatory power of each VOC in the different scenarios. Receiver operating characteristic (ROC) curves were constructed to assess the discriminatory power of the biomarkers for lung function decline.

Exhaled breath of 45 asthmatics was analyzed. Patient characteristics and baseline lung function parameters are presented in Table 1. Twenty-five patients (56\%) were airflow decliners over a 5 -year period and 20 patients (44\%) were non-decliners. Looking at baseline characteristics, we did not find any significant difference between groups regarding gender, age, age of onset, BMI, smoking history, baseline $\mathrm{FEV}_{1}$, FeNO, sputum eosinophil and neutrophil counts, Asthma Control Questionnaire or blood eosinophils 
and neutrophils, exacerbations, hospitalizations in the last 12 months, or treatment regimen. Fifty-four percent of airflow decliners were receiving high ICS daily doses, as compared to $25 \%$ in the non-decliners. OCS maintenance treatment was present in $16 \%$ of airflow decliners versus $10 \%$ in non-decliners. Sixty percent of decliners and $75 \%$ of non-decliners were treated with long-acting $\beta 2$ agonists. Twenty percent of decliners versus $5 \%$ of non-decliners were receiving long-acting anti-muscarinic agent therapy.

According to ERS/ATS criteria, ${ }^{8} 40 \%$ of these patients were severe asthmatics. Eight of them were started on biologic therapy during the study. Three of them were still part of the airflow decliners group. Sputum inflammatory phenotypes and inhaled corticosteroid doses were quite stable over time.

Based on a set of 640 VOCs, the comparison of these two groups revealed no difference between airflow decliners and non-decliners. Moreover, no difference between groups was observed based on the 25 VOCs with the highest classification performance. With a Random Forest estimated prediction error of $48.6 \%$, no significant discrimination could neither be shown between the two groups. ROC curves for the prediction of $\mathrm{FEV}_{1}$ decline using $5,10,15,25,50,100$ VOCs had AUC of 0.529 , $0.533,0.545,0.538,0.547,0.544$, respectively (Figure 1).

Although Lazar et $\mathrm{al}^{9}$ previously found that bronchoconstriction after methacholine challenge did not affect Breathprint using eNose, we hypothesized that VOCs could discriminate between airflow decliners and nondecliners as several cytokines and inflammatory cells may play a role in airflow decline. Our study is the first attempt to relate exhaled VOC profiles to lung function decline in asthmatic patients over 5 years. According to our results, VOCs are not able to discriminate between airflow decliners and non-decliners. In our study, airflow decliners and non-decliners had similar levels of FeNO,

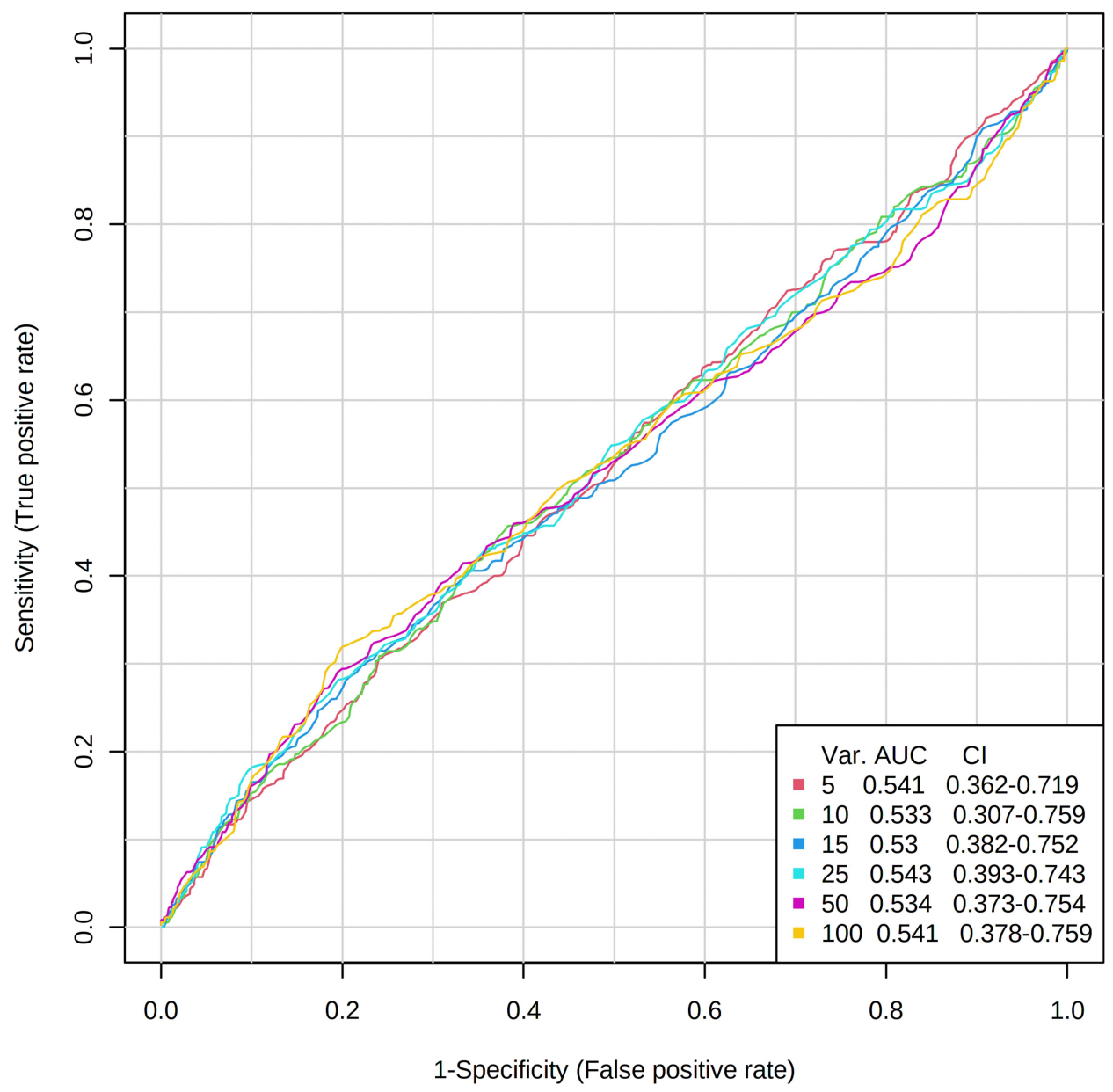

Figure I Area under the receiver operating characteristic curves from the conditional inference forest binary classification of decliners versus non-decliners using 5 , I0, I5, $25,50,100$ VOCs of highest classification performance.

Abbreviation: AUC, area under the curve. 
blood and sputum eosinophils at baseline. It has already been shown that VOCs reflect airway inflammation. ${ }^{4}$ Our observations bring out that exhaled VOCs are possibly more to be considered as a reflection of the inflammatory mechanism rather than an airway caliber. Our results should be confirmed in a larger cohort using multiple VOC measurements over a longer period of time to see if the change in VOC levels over time can reflect $\mathrm{FEV}_{1}$ decline and if other variables may affect the relationship between VOC measurements and lung function.

\section{Disclosure}

Prof. Dr Renaud Louis reports grants and/or personal fees from GSK, AZ, Novartis, Chiesi, and Sanofi, outside the submitted work. The authors report no other conflict of interest with this work.

\section{References}

1. Lange P, Parner J, Vestbo J, et al. A 15-year follow-up study of ventilatory function in adults with asthma. $N$ Engl J Med. 1998;339 (17):1194-1200. doi:10.1056/NEJM199810223391703
2. Broekema M, Volbeda F, Timens W, et al. Airway eosinophilia in remission and progression of asthma: accumulation with a fast decline of FEV (1). Respir Med. 2010;104:1254-1262. doi:10.1016/j.rmed.2010.03.030

3. Graff S, Demarche S, Henket M, et al. Increase in blood eosinophils during follow-up is associated with lung function decline in adult asthma. Respir Med. 2019;152:60-66. doi:10.1016/j.rmed.2019.04.020

4. Schleich FN, Zanella D, Stefanuto P-H, et al. Exhaled volatile organic compounds are able to discriminate between neutrophilic and eosinophilic asthma. Am J Respir Crit Care Med. 2019;200(4):444-453. doi:10.1164/rccm.201811-22100C

5. Schleich FN, Dallinga JW, Henket M, et al. Volatile organic compounds discriminate between eosinophilic and neutrophilic inflammation in vitro. J Breath Res. 2016;10(1):016006. doi:10.1088/1752-7155/10/1/016006

6. Garcia-Marcos L, Edwards J, Kennington E, et al. Priorities for future research into asthma diagnostic tools: A PAN-EU consensus exercise from the European asthma research innovation partnership (EARIP). Clin Exp Allergy. 2018;48(2):104-120. doi:10.1111/cea.13080

7. Hothorn LA. How to deal with multiple treatment or dose groups in randomized clinical trials? Fundam Clin Pharmacol. 2007;21 (2):137-154. doi:10.1111/j.1472-8206.2007.00469.x

8. Chung KF, Wenzel SE, Brozek JL, et al. International ERS/ATS guidelines on definition, evaluation and treatment of severe asthma. Eur Respir J. 2014;43(2):343-373. doi:10.1183/09031936.00202013

9. Lazar Z, Fens N, van der Maten J, et al. Electronic nose breathprints are independent of acute changes in airway caliber in asthma. Sensors (Basel). 2010;10:9127-9138. doi:10.3390/s101009127

\section{Publish your work in this journal}

The Journal of Asthma and Allergy is an international, peer-reviewed open-access journal publishing original research, reports, editorials and commentaries on the following topics: Asthma; Pulmonary physiology; Asthma related clinical health; Clinical immunology and the immunological basis of disease; Pharmacological interventions and new therapies. The manuscript management system is completely online and includes a very quick and fair peer-review system, which is all easy to use. Visit http://www.dovepress.com/testimonials.php to read real quotes from published authors. 